\title{
Modification of the Thermoset Injection Moulding Process for Shaping to Increase the Fibre Length in C/C-SiC Ceramics Produced by the LSI Process
}

\author{
Jonas Stiller ${ }^{1, a *}$, Daisy Nestler ${ }^{1, b}$, Erik Päßler ${ }^{1, c}$, Fabian Kempe $^{2, d}$ \\ Hendrik Wätzig ${ }^{1, \mathrm{e}}$, Husam Ahmad ${ }^{3, \mathrm{f}}$, Lothar Kroll ${ }^{1, \mathrm{~g}}$, Michael Sommer ${ }^{2, \mathrm{~h}}$, \\ Guntram Wagner ${ }^{3, i}$ \\ ${ }^{1}$ Department of Lightweight Structures / Polymer Technology, Chemnitz University of \\ Technology, 09107 Chemnitz, Germany \\ ${ }^{2}$ Department of Polymer Chemistry, Chemnitz University of Technology, 09107 Chemnitz, \\ Germany \\ ${ }^{3}$ Department of Composites and Material Compounds, Chemnitz University of Technology, \\ 09107 Chemnitz, Germany \\ ajonas.stiller@mb.tu-chemnitz.de, bdaisy.nestler@mb.tu-chemnitz.de, \\ cerik.paessler@mb.tu-chemnitz.de, ${ }^{\mathrm{d}} F$ abian.kempe@chemie.tu-chemnitz.de, \\ eHendrik.waetzig@mb.tu-chemnitz.de, fhusam.ahmad@mb.tu-chemnitz.de, \\ glothar.kroll@mb.tu-chemnitz.de, 'nmichael.sommer@chemie.tu-chemnitz.de, \\ 'guntram.wagner@mb.tu-chemnitz.de
}

Keywords: Thermoset injection moulding, Fibre length analysis, ceramic-matrix composite.

\begin{abstract}
Ceramic-matrix composites (CMC) made of carbon and silicon carbide dual matrix reinforced with carbon fibres $(\mathrm{C} / \mathrm{C}-\mathrm{SiC})$ have exceptional heat, thermal shock, creep, and wear resistance, while also having little density and high strength. In comparison to monolithic ceramics, CMC possess ductility and damage tolerance, which opens this material for severe applications. Starting in space applications, this material is today well established in friction applications, where lightweight high-performance brakes securely decelerate e.g. luxury cars or elevators. The high production costs still limit the broad application like as brake discs in standard passenger cars, although less weight, better performance and longer lifetime. The industrial used production process is the liquid silicon infiltration (LSI) with it three steps: green body shaping, pyrolysis and silicon infiltration. In this work, the shaping process of the carbon fibre reinforced plastic (CFRP) green body, is done by thermoset injection moulding. The application of plastic production processes like compounding and injection moulding in the liquid silicon infiltration process route, enables largescale manufacturing. However, the screws and high shear forces inside the plastic processing machines significantly shorten the fibres. This paper describes the pros and cons of thermoset injection moulding in the LSI route, as well as the development and effect of different reinforcement types in dependence of their fibre length, since several energy dissipation mechanisms bases on a minimum length of reinforcement fibres in CMC. Various raw materials like short and chopped fibres with different length, rovings, and different approaches to receive longer fibres and their outcomes are presented. The mechanical properties show promising values and the micrographs display the infiltration status and crack development inside the specimen.
\end{abstract}

\section{Introduction}

The LSI process is the commercial production method for $\mathrm{C} / \mathrm{C}-\mathrm{SiC}$-based ceramic matrix composites [1]. In general, the process is divided into three parts: the shaping of a carbon fibre reinforced plastic (CFRP) green body, the subsequent pyrolysis into a carbon/carbon (C/C) composite and the final infiltration with molten silicon to $\mathrm{C} / \mathrm{C}-\mathrm{SiC}$ [2]. The production of CFRP structures can be carried out by conventional processes such as hot pressing, resin-transfer moulding or hand lamination $[3,4]$. However, all processes are based on a high proportion of manual work and have only limited possibilities for the realisation of complex geometries. In addition, the processes, apart 
from hot pressing, are only designed for small series. These manufacturing restrictions also result in the high price of $\mathrm{CMC}$ and their limited application, which is to be changed by the development of new production processes. In comparison to the common warm pressing process, in this work, the first step is done by thermoset injection moulding. This enables large-scale manufacturing of CRFP green bodies [5]. For this purpose, injection mouldable carbon fibre reinforced phenolic resin granulate is produced which can be thermoplastically processed in compounders and injection moulding machines. The cross-linking and curing happens in the injection mould. The processing greatly reduces the fibre length due to the screws and the high shear forces. Previous investigations regarding the use of additional chopped fibres which were directly added into the injection moulding machine and of nonwoven inserts in the mould [4] have not yielded the desired increases in mechanical properties, such as bending strength, but in some cases quasi-ductile fracture behaviour has been observed. Since the strength and especially the ductility depends on the length of the fibres [2], the aim of the tests is to shorten the fibres as little as possible. The basis for the presented tests is a larger compounder, which should achieve gentle processing with homogeneous mixing. All components are gravimetrically dosed so that an exact recipe and a homogeneous distribution are assumed. An adapted geometry of the individual screw elements as well as the screw tips and tool design ensure gentle processing without accumulation zones and undercuts.

The investigation of the fibre length in the produced compound is achieved by dissolving the noncrosslinked matrix. This is done in an acetone bath and for comparison reasons in a Soxhlet extractor. The resulting fibre lengths is analysed automatized and evaluated.

\section{Experimental}

Material. The carbonaceous precursor material is the commercial combination from Prefere Resins Germany $\mathrm{GmbH}$, a phenolic novolak resin with dropping point of $120{ }^{\circ} \mathrm{C}$ and hardener hexamethylenetetramine (HTMA) for crosslinking. For processability, Zinc stearate from Bearlocher $\mathrm{GmbH}$ was added as lubricant. Altogether, this work compares six materials. The first material serves as a benchmark for the previous manufacturing process. In this so-called reference material, Zoltek carbon fibres, above-mentioned phenolic resin with lubricant are used from previous experiments [6]. Material A, B, C and D uses the reinforcement fibres Sigrafil from SGL Group which are 3 and $6 \mathrm{~mm}$ chopped carbon fibres (based on 50k heavy tow). The ingredients are mixed in a co-rotating twinscrew extruder ERMAFA E2.30 from ERMAFA Maschinen- und Anlagenbau GmbH with a screw diameter of $\mathrm{D}=30 \mathrm{~mm}$ and a processing length of $45 \mathrm{D}$. At first, the powdery novolak and the lubricant are gravimetrically dosed into the compounder and molten. Secondly, the dosing unit adds the fibres by gravity where the screws mix them with the novolak. Therefore, the adjustment of a certain fibre volume content is possible. Shortly before passing the nozzle, the hardener is added, early enough to get a homogenised compound and late enough to prevent the premature crosslinking. After passing the nozzle, a hot pelletising unit chops the compound into granules and an airflow cools and transports them. For material E, $25 \mathrm{wt} . \%$ chopped carbon fibres are added to the reference material, so that the theoretical fibre content is approx. $60 \%$, as already described in [7]. In addition, a newly developed low-viscosity phenolphenyl resin, which is intended to reduce the proportion of lubricant, because it is expected to have a slightly lubricating effect. This replaces $10 \%$ of the novolak in material F. Table 1 gives an overview of the different material compositions. 
Table 1: Material compositions.

\begin{tabular}{|c|c|c|c|c|c|c|c|c|}
\hline \multicolumn{2}{|c|}{ Samples } & Reference & $\begin{array}{c}\mathrm{A} \\
50-6\end{array}$ & $\begin{array}{c}\mathrm{B} \\
58-6\end{array}$ & $\begin{array}{c}\mathrm{C} \\
50-3\end{array}$ & $\begin{array}{c}\mathrm{D} \\
58-3\end{array}$ & E $50-25-6$ & F 50-6 \\
\hline \multicolumn{2}{|c|}{ Matrix } & \multicolumn{6}{|c|}{42 wt.\% novolak, 7 wt.\% HTMA and 1 wt.\% lubricant } & $\begin{array}{l}38 \text { wt.\% novolak, } \\
4 \mathrm{wt} \% \text { phenylphenol, } \\
7 \mathrm{wt} \% \text { HTMA and } \\
1 \mathrm{wt} \% \text { lubricant }\end{array}$ \\
\hline \multicolumn{2}{|c|}{ Fibre dosing } & From roving & \multicolumn{5}{|c|}{ Chopped fibres } & Chopped fibres \\
\hline \multirow{2}{*}{$\begin{array}{l}\text { Fibre } \\
\text { content }\end{array}$} & wt. $\%$ & \multirow{2}{*}{$\begin{array}{l}\text { Not precise/ } \\
\text { nominal } 50\end{array}$} & 50 & 58 & 42 & 58 & 60 & 50 \\
\hline & vol. $\%$ & & 42 & 50 & 50 & 42 & 52 & 42 \\
\hline \multicolumn{2}{|c|}{$\begin{array}{l}\text { Fibre length } \\
\quad[\mathrm{mm}]\end{array}$} & $\begin{array}{l}\text { Endless from } \\
\text { the roving }\end{array}$ & \multicolumn{2}{|c|}{6} & \multicolumn{2}{|c|}{3} & $\begin{array}{c}\text { like } \\
\text { reference } \\
\text { with } \\
\text { additional } 6\end{array}$ & 6 \\
\hline
\end{tabular}

Methods. From all combinations except F, bending specimens with dimensions of 50 x 10 x $3 \mathrm{~mm}$ with a tapered sprue and an overflow were injection moulded. Those specimen were produced in an injection moulding machine type Arburg Allrounder 220S 150-60. The cylinder has three zones of temperature control; the feeding zone is tempered to $70^{\circ} \mathrm{C}$, and the plasticisation and the nozzle zone to $90{ }^{\circ} \mathrm{C}$, the tool has $175^{\circ} \mathrm{C}$. The cavity is filled within six seconds, and the injection pressure is $906 \pm 52$ bar in average. The curing time is $70 \mathrm{~s}$; the total cycle time is about $90 \mathrm{~s}$ (injecting, curing, ejecting and cleaning). The specimen size of Material $\mathrm{F}$ is $50 \times 8 \times 3 \mathrm{~mm}$. For this experimental mixture, a Plasti-Corder PL2000 from Brabender mixes the ingredients, which are later injected with the Thermo Scientific HAAKE MiniJet II. The cylinder has $110^{\circ} \mathrm{C}$ and the cavity is heated to $180{ }^{\circ} \mathrm{C}$. The subsequent pyrolysis and silicon infiltration and the results are not part of this work.

The fibre length in plastics is determined by separating the fibres from the matrix. A piece of the strand leaving the nozzle of the injection moulding machine is used as a sample. At this point, the components have already passed through two plastic processing machines, so that a homogeneous distribution of the individual components can be assumed. For the separation of the fibres, samples are placed in an acetone bath to dissolve the matrix and put in a laboratory shaker for 30 min. To accelerate the dissolution and separation, the samples are put in a Petri dish filled with acetone in and placed in an ultrasonic bath. Some specimens of the reference samples and E were additionally added to a Soxhlet extractor. After the matrix is dissolved, the dissolved fibres are placed in demineralised water before being placed in a Petri dish. This is inserted into a FASEP fibre scanner from E. KARG Industrietechnik. The image (s. Fig. 1) is then automatically evaluated and the fibre length distribution output.

The characterisation of the fibre length in thermosetting materials with a high carbon yield is tricky. For the separation of the fibres a Soxhlet extractor with acetone was used. For comparison, petri dishes filled with acetone were put in an ultrasonic bath to disintegrate the unlinked resin. 


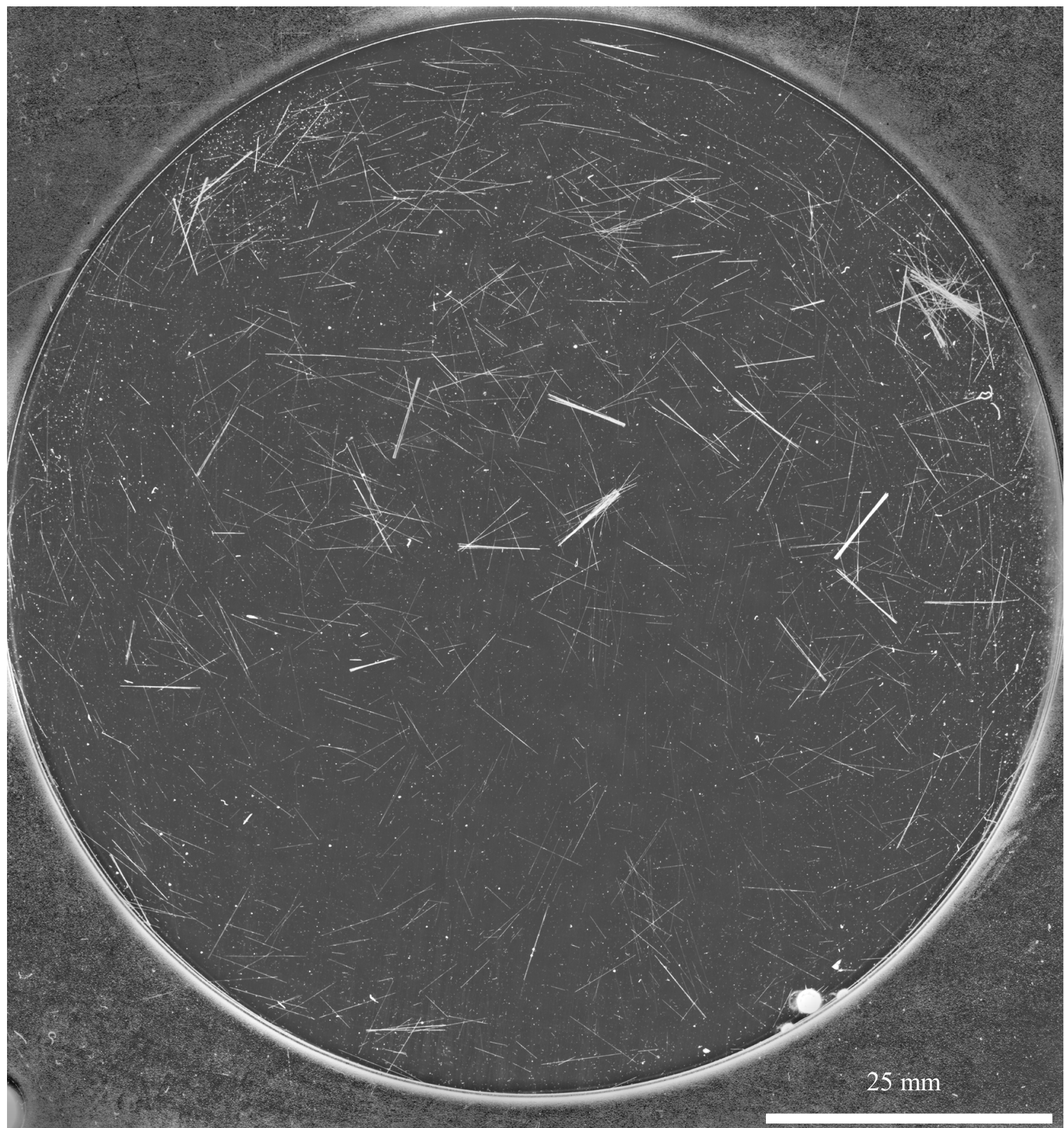

Fig. 1: Scan image of petri dish with diameter of $92 \mathrm{~mm}$ of material E. Fibres are white.

\section{Results and Discussion}

The fibre length of all samples has been significantly reduced by processing up to the nozzle of the injection moulding machine.

There are two methods for the analysis of the fibre length. The first counts short fibres and the second long fibres. The short fibre method recognises fibres with a length of $25 \mu \mathrm{m}$ or more that are completely straight. Curved fibres are ignored. The long fibre method counts fibres longer than from $100 \mu \mathrm{m}$ length, whereby these can also be bent. With both methods, only fibres that are completely within the analysis range are counted, crossing points are detected. The analysis software sorts the fibre lengths into so-called classes. The value range between the upper limit, which is given by the longest measured fibre, and the lower limit is divided into 80 classes. A class comprises a length range in which the measured fibres are classified. The number of fibres in each class is output as a number-mean frequency. Since the fibres with very small lengths are most present, but their effect is not equivalent with the effect of the few longer fibres, e.g. for the mechanical properties, the volume- 
mean frequency is used. Fig. 2 shows these two frequency distributions for a short and a long fibre measurement. The shift of the curves to higher length classes from number- to volume-mean represents the qualitative effect of the longer fibres.

a) Quality frequencies of fibre length

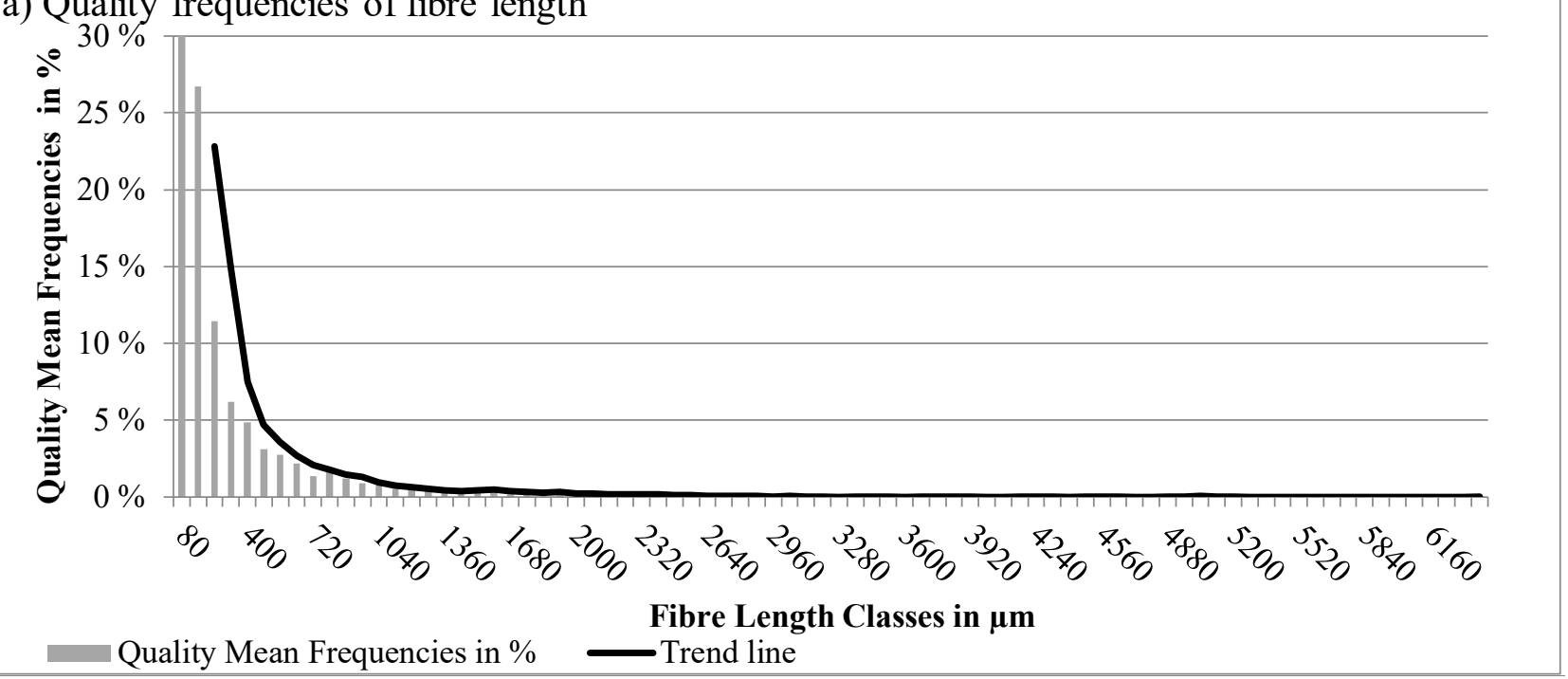

b) Volume frequencies of fibre length

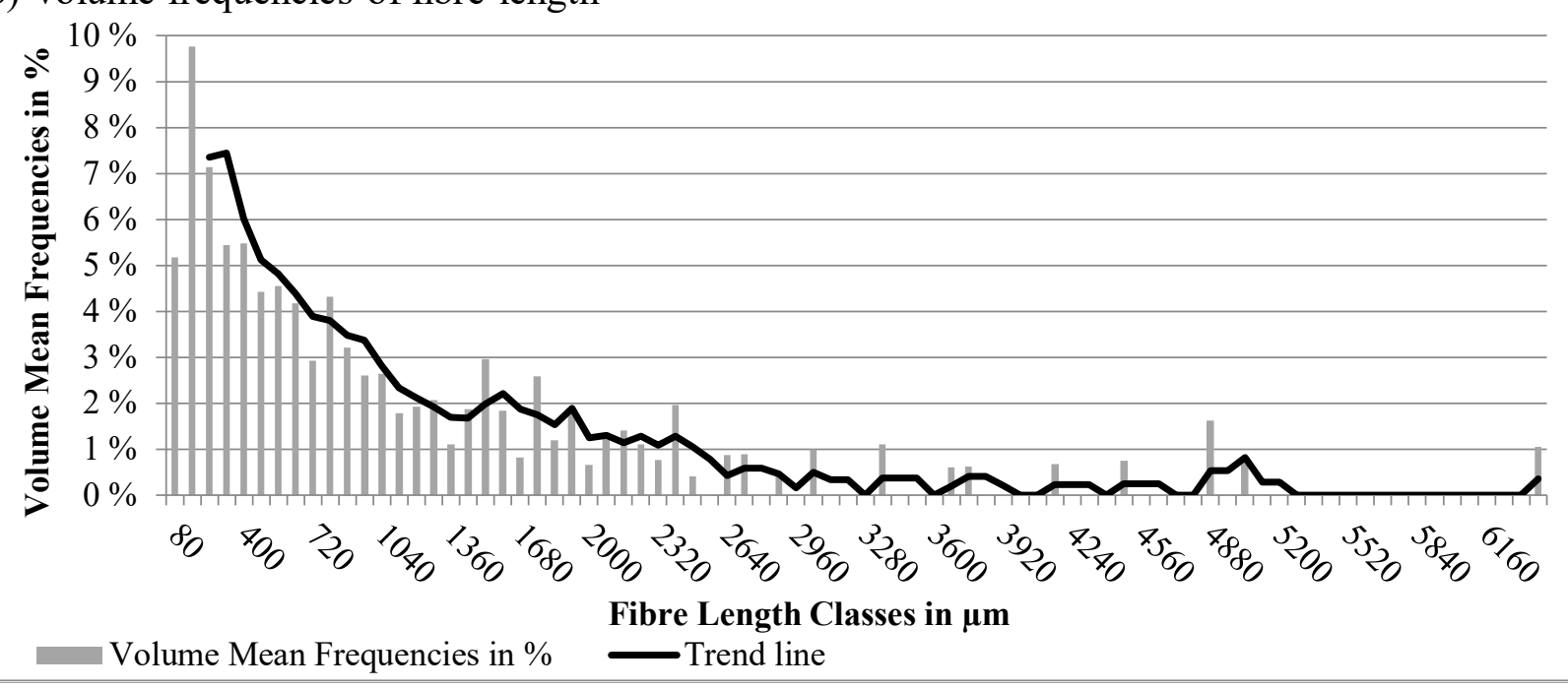

c) Quality frequencies of fibre length

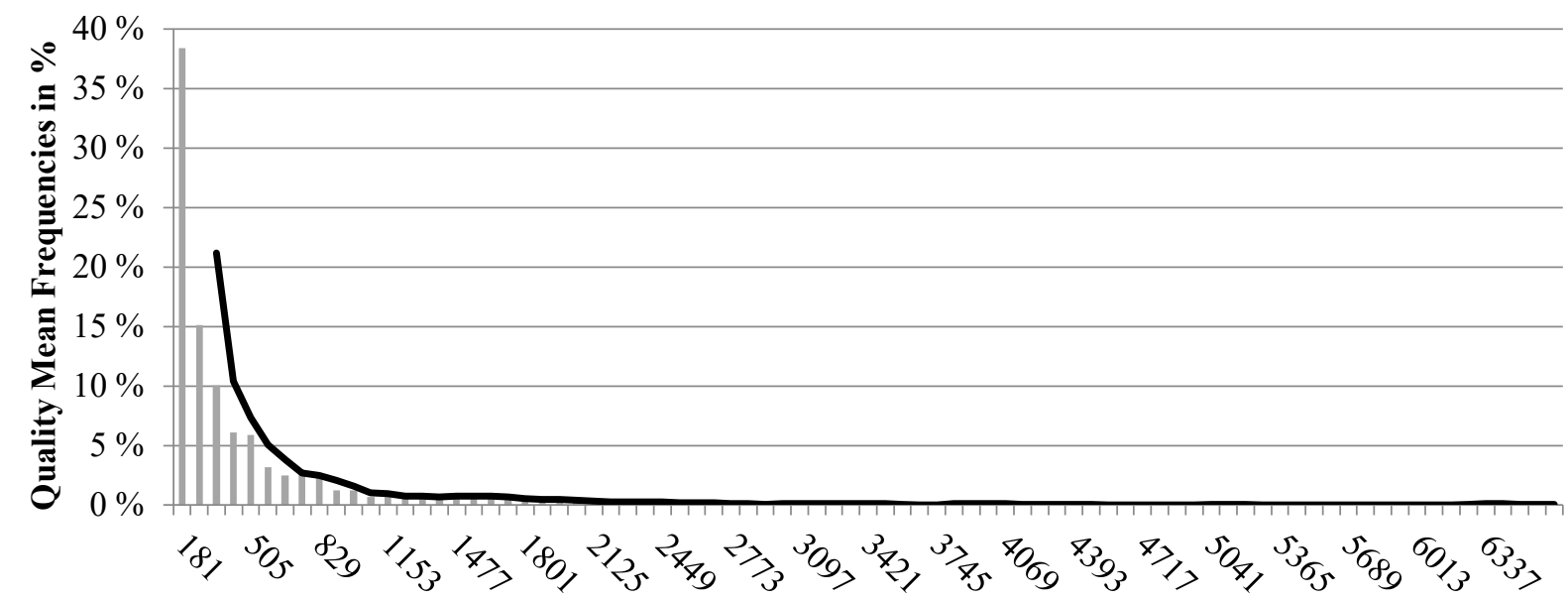


d) Volume frequencies of fibre length

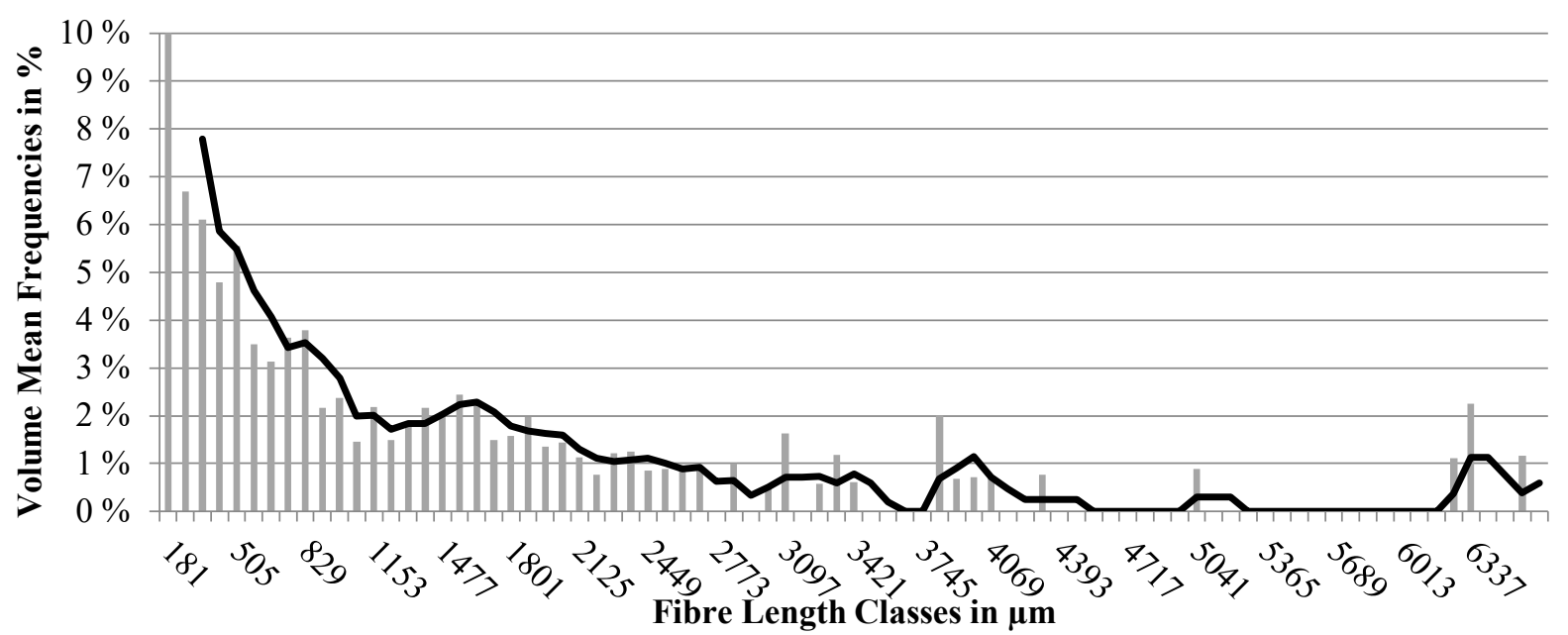

Volume Mean Frequencies in \% Trend line

Fig. 2: Number and volume mean fibre length distribution of material E. a) Shows the quantity frequencies of short fibre analysis, b) shows the volume frequencies of short fibre analysis, c) shows the quantity frequencies of long fibre analysis, and d) shows the volume frequencies of long fibre analysis.

For the various materials in Table 1, the number- and volume-averaged fibre lengths are shown in Table 2 . The high scatters come from the individual batches, as only approx. $1 \mathrm{~cm}$ of the strand or 2-3 granules are used for analysis. For a better statistical evaluation, the number of measurements must be significantly increased.

Table 2: Comparison of individual resulting fibre lengths (all long fibre analysis method).

\begin{tabular}{|c|c|c|c|c|c|c|c|c|c|}
\hline Name & Reference & \begin{tabular}{|l|}
$\begin{array}{l}\text { Soxhlet of } \\
\text { reference }\end{array}$ \\
\end{tabular} & A 50-6 & B 58-6 & C 50-3 & D 58-3 & E 50-25-6 & Soxhlet of E & F 50-6 \\
\hline $\begin{array}{l}\text { Quantity mean } \\
{[\mu \mathrm{m}]}\end{array}$ & 209.7 & 202.1 & 261.6 & 249.4 & 271.3 & 252.7 & 320.9 & 344.5 & 262.2 \\
\hline $\begin{array}{l}\text { Standard } \\
\text { derivation }[\mu \mathrm{m}]\end{array}$ & 7.9 & 12.4 & 2.7 & 5.9 & 5.6 & 18.9 & 84.3 & 44.8 & 13.1 \\
\hline $\begin{array}{l}\text { Volume mean } \\
{[\mu \mathrm{m}]}\end{array}$ & 276.4 & 265.3 & 446.3 & 497.6 & 482.1 & 467.6 & 850.5 & 992.3 & 382.2 \\
\hline $\begin{array}{l}\text { Standard } \\
\text { derivation }[\mu \mathrm{m}]\end{array}$ & 15.6 & 23.9 & 28.6 & 35.4 & 9.9 & 57.0 & 253.0 & 154.0 & 26.8 \\
\hline $\begin{array}{l}\text { Average number } \\
\text { of fibres }\end{array}$ & 18124 & 7769 & 14060 & 9434 & 10357 & 10619 & 6447 & 10547 & 18858 \\
\hline
\end{tabular}

In the comparison of the materials with the reference, a significant increase in fibre lengths could be achieved. Especially the additional cut fibres in material $\mathrm{E}$ introduced into the injection moulding machine show a doubling of the volume-mean fibre length compared to materials $\mathrm{A}, \mathrm{B}, \mathrm{C}$ and $\mathrm{D}$ and even a quadrupling compared to the reference. The four materials (A, B, C, and D) differ only slightly in terms of both number and volume-mean fibre length. The influence of the initial fibre length on the resulting fibre length is only slight when using the above-mentioned machines.

For material F, the quantity-mean fibre length is in the range of materials A to D, but the volumemean fibre length is significantly lower. Since direct comparison is not feasible due to the different used machines, it becomes clear that even on a laboratory-scale, strong fibre reductions can be achieved and larger free volumes are required for gentle processing. The additional phenylphenol resin was added to test its lubricating effect. The tests completely without lubricant were performed. The mixing was successful, but the further testing was aborted, because the material stuck strongly to the tool walls and the kneading blades and bemoulding was not possible. This is not discussed further here. 
When using the Soxhlet extractor, the fibres are gently removed from the matrix. There is no mechanical stress on the fibres except when handling the samples, unlike with ultrasound or laboratory shakers. The results are longer mean values and smaller standard deviations between the individual measurements.

The determination of the fibre length in the finished component, the $\mathrm{C} / \mathrm{C}$-SiC state, is only possible through complex and inadequate optical methods such as microstructure analysis. Even in the thermoset state, i.e. in the cross-linked and cured state, it is no longer possible to separate the fibres from the matrix. Therefore, the strand is used after leaving the injection nozzle. In the further process sequence, the melt then flows through the sprue channel and the gate into the cavity. Very high shear forces act, since the material fills the cavity within a few seconds with injection pressures of approx. 1000 bar. Since cross-linking takes place in the hot mould, viscosity is reduced during the injection process before the melt cross-links from the mould wall to the centre and thus solidifies [8]. In order to measure the correct fibre length in the mould, a cold mould would have to be used, just like in thermoplastic processing. However, this would increase the viscosity during injection, which would cause other shear forces to act on the melt and fibres during the injection process. Therefore, the use of the melt strand after leaving the injection moulding machine is a conscious compromise, which can be controlled by measurements on a random basis in the microscopic images.

Although fibre bundles of approx. $6 \mathrm{~mm}$ in length are clearly visible in Fig. 1, the software does not recognise them. The separation of the bundles is a complex process, since the use of tweezers or similar can severely damage the fibres. Since these bundles are visible in the finished component even after the injection moulding process [6], they must be taken into account in the evaluation of the fibre length.

\section{Conclusions}

The reduction of the fibre length in the production of CFRP green bodies for the manufacture of ceramic matrix composites is a consequence when using thermoset injection moulding. In order to generate the energy dissipation effects, a certain fibre length is required, so that the preservation of the fibre length must be at the core of research of this technology.

The automated fibre length analysis represents a significant advance, but the pure numbers can only be correctly evaluated by taking the recorded images into account. The difference between the 3 and $6 \mathrm{~mm}$ long fibres and fibre volume contents between 50 and $58 \mathrm{wt} . \%$ is marginal, but the later processing properties of the higher fibre contents are worse. In addition, the $6 \mathrm{~mm}$ variant in the $\mathrm{C} / \mathrm{C}$ $\mathrm{SiC}$ state has higher mechanical properties [9], which is why it will be used in the next tests. The more complex Soxhlet extraction has proven to be a better method, which is why it should continue to be used in the future.

\section{Acknowledgements}

Funding: This work was performed as part of the research project FiberCer (grant number 100310496), supported by the European Social Fund (ESF). Financial support is gratefully acknowledged.
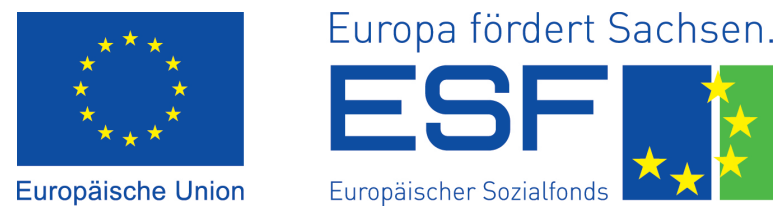

\section{References}

[1] W. Krenkel, Cost Effective Processing of CMC Composites by Melt Infiltration (LSI-Process), Ceramic Engineering and Science Proceedings 22 (3) (2001) 443-454.

[2] W. Krenkel, From Polymer to Ceramics: Low Cost Manufacturing of Ceramic Matrix Composite Materials, Molecular Crystals and Liquid Crystals Science and Technology. Section A. Molecular Crystals and Liquid Crystals 354 (1) (2000) 353-364.

[3] W. Krenkel, B. Heidenreich, R. Renz, C/C-SiC Composites for Advanced Friction Systems, Adv. Eng. Mater. 4 (7) (2002) 427-436. 
[4] N.P. Bansal, J. Lamon (Eds.), Ceramic matrix composites: Materials, modeling and technology, Wiley, Hoboken, 2015.

[5] N. Nier, D. Nestler, K. Roder, A. Todt, E. Päßler, J. Weißhuhn, H. Würfel, S. Spange, L. Kroll, G. Wagner, Großserientaugliche Formgebung durch Duroplast-Spritzgießen zur Herstellung von faserverstärkter Keramik, Keram. Z. 68 (1) (2016) 48-50.

[6] D. Nestler, N. Nier, K. Roder, E. Päßler, J. Weißhuhn, A. Todt, H. Würfel, L. Kroll, S. Spange, B. Wielage, G. Wagner, Development and Characterisation of Phenolic Resin Moulding Materials for the Production of New Short Fibre-Reinforced C/C-SiC Composites, Mater. Sci. Forum 825-826 (2015) 215-223.

[7] J. Stiller, D. Nestler, H. Ahmad, E. Päßler, G. Wagner, L. Kroll, New large-scale production method for $\mathrm{C} / \mathrm{C}-\mathrm{SiC}$ ceramics: Investigating the influence of chopped and nonwoven $\mathrm{CF}$, Ceramics International (Article in press) (2018).

[8] S. Englich, Strukturbildung bei der Verarbeitung von glasfasergefüllten Phenolformaldehydharzformmassen. Dissertation, Chemnitz, 2015.

[9] H. Ahmad, J. Stiller, E. Päßler, D. Nestler, G. Wagner, L. Kroll, Influence of initial fiber length and content used in the injection mould-ing of CFRP on the properties of $\mathrm{C} / \mathrm{C}$ and $\mathrm{C} / \mathrm{C}-\mathrm{SiC}$ composites, Scienfitic.net, Proceedings of 22 nd symposium of composites, paper submitted, (2019). 